ISSN 1518-3483

Licenciado sob uma Licença Creative Commons

(c) (i)

\title{
Estratégias católicas de formação de professores e circulação de modelos culturais e pedagógicos no Brasil e em Portugal
}

Catholic strategies for teacher training and the circulation of cultural and pedagogical models in Brazil and Portugal

\section{Evelyn de Almeida Orlando[a], Maria João Mogarro ${ }^{[b]^{*}}$}

[a] Pontifícia Universidade Católica do Paraná (PUCPR), Curitiba, PR, Brasil

[b] Instituto de Educação da Universidade de Lisboa, Lisboa, Portugal

\section{Resumo}

Este artigo trata das estratégias católicas de formação docente utilizadas no Brasil e em Portugal a partir da circulação de modelos culturais e pedagógicos que contribuiu para configurar os debates e as práticas educacionais nesses dois países. Dois periódicos foram considerados como fontes privilegiadas neste trabalho: O Boletim Catequético e o Boletim Escola Portuguesa. Ambos, destinados a professores, foram analisados considerando as estratégias de produção e práticas discursivas mobilizadas por esses periódicos com o

* EAO: Doutora, e-mail: evelynorlando@gmail.com

MJM: Doutora, e-mail: mariamogarro@gmail.com 
objetivo de formar um perfil de professor que conjugava em si valores e comportamentos coerentes com os projetos educacionais do Estado e da Igreja. O aporte teórico metodológico se apoiou nas representações e nas práticas discursivas desses dois boletins, considerando a circulação de saberes pedagógicos que serviram para configurar saberes inerentes à formação e à profissão docente, a partir da ótica de Nóvoa (1987), Mogarro (2001), Pintassilgo (2011, 2012) e Pintassilgo, Mogarro \& Henriques (2010, 2012). A análise desses periódicos permitiu verificar que os projetos educacionais veiculados pelos católicos, tanto no Brasil quanto em Portugal, se valeu de uma amálgama de várias fôrmas para instituir um projeto de educação eficaz em sintonia com os princípios dos regimes de cada país.

Palavras-chave: Circulação de modelos culturais. Impressos. Formação de professores.

\section{Abstract}

This article addresses Catholic strategies for teacher training used in Brazil and Portugal, based on the circulation of cultural and pedagogical models that have helped to configure educational debates and practices in these two countries. Two periodicals, both intended for teachers, were considered as main sources in this work: the (Brazilian) Catechetical Bulletin and the Portuguese School Bulletin. Both periodicals were analyzed with a focus on the production strategies and discursive practices they mobilized to create a profile of the teaching profession or role that unites values and behavior in a way consistent with the educational projects of the Church and State. The methodology is supported theoretically on the basis of the representations and discursive practices of these two bulletins, in terms of the circulation and configuration of pedagogical knowledge inherent to teacher training and the teaching profession, from the perspectives of Nóvoa (1987), Mogarro (2001), Pintassilgo (2011; 2012), and Pintassilgo, Mogarro, and Henriques (2010; 2012). The analysis of the periodicals showed that educational projects disseminated by Catholics and Catholic organizations, in both Brazil and in Portugal, use an amalgamation of different forms to institute an effective educational project in line with the principles of the systems in each country.

Keywords: Circulation of cultural models. Printed matter. Teacher training. 


\section{Introdução}

Este artigo trata das estratégias católicas de formação docente utilizadas no Brasil e em Portugal, a partir da circulação de modelos culturais e pedagógicos que contribuíram para configurar os debates e as práticas educacionais nesses dois países. Dois periódicos foram considerados como fontes privilegiadas neste trabalho: O Boletim Catequético e o Boletim Escola Portuguesa. Ambos, destinados a professores. Considerando as estratégias de produção e práticas discursivas mobilizadas por esses periódicos, com o objetivo de formar um perfil de professor que conjugava em si valores e comportamentos coerentes com os projetos educacionais do Estado e da Igreja.

A pesquisa aqui empreendida nessa relação com Portugal iniciou à época do doutorado, no "sanduíche" realizado sob a supervisão da professora Maria João Mogarro ${ }^{1}$, onde buscou-se compreender as estratégias católicas de formação de professores articuladas ao movimento da Escola Nova, considerando tanto no Brasil e em Portugal a apropriação feita pelos intelectuais católicos em relação ao movimento escolanovista, tendo como principal escopo a circulação dos saberes que configuraram esse movimento.

A investigação teve como ponto de partida as ações pedagógicas do Monsenhor Álvaro Negromonte, intelectual e educador católico brasileiro que atuou de forma expressiva entre os anos de 1930 e 1960, no Brasil, a partir dos estados de Minas Gerais e do Rio de Janeiro. Suas ações, no entanto, alcançaram todo o território nacional e seus livros indiciam movimentos de diálogos e de circulação de seus textos com outros países. No percurso da pesquisa, muitos caminhos foram aparecendo como possibilidade de aprofundar essa história do movimento de circulação dos saberes pedagógicos no âmbito internacional.

1 Essa pesquisa foi realizada em um primeiro momento com financiamento da CAPES, em 2011 e retomada, sob um enfoque mais ampliado, em 2015, a partir do projeto "Igreja Católica e circulação de saberes pedagógicos intelectuais, impressos e práticas educativas", com financiamento do CNPQ. 
Portugal foi escolhido como um caminho interessante para ampliar esse olhar, porque, além de revelar indícios de circulação de algumas das obras do padre, permitia maior aprofundamento do diálogo que os católicos fizeram do movimento escolanovista, pondo em evidência estratégias similares de formação docente no âmbito dos impressos e da inovação pedagógica. Assim, na cidade de Lisboa, durante cinco meses, investigamos o periódico Boletim Escola Portuguesa, buscando compreender essa fonte pela lente da bibliografia produzida pelos historiadores da educação daquele país, sobretudo aqueles trabalhos que enfocaram o movimento da Educação Nova em Portugal.

A pretensão não foi realizar um estudo comparativo, mas aprofundar uma temática que, no Brasil, ainda não é consensual acerca de um escolanovismo católico; e perceber, nesse contexto, como os educadores católicos mobilizaram um conjunto de estratégias para a formação do professorado, buscando apreender os modelos culturais que, através de diferentes dispositivos de circulação, incidiram na construção de um repertório de saberes autorizados e contribuíram para colocar a pedagogia católica no âmbito das inovações pedagógicas.

O aporte teórico metodológico se apoiou nas representações e nas práticas discursivas desses dois boletins, considerando a circulação de saberes pedagógicos que serviram para configurar saberes inerentes à formação e à profissão docente a partir da ótica de Nóvoa (1987), Mogarro (2001), Pintassilgo (2011, 2012) e Pintassilgo, Mogarro \& Henriques (2010, 2012). Apesar de não pretender estabelecer uma análise em uma perspectiva comparada, as similitudes entre os contextos e as estratégias utilizadas acabaram emergindo, muitas vezes, sinalizando para pontos de contato entre as práticas de difusão e circulação dos modelos pedagógicos católicos entre os anos de 1930/1940 tanto no Brasil quanto em Portugal².

2 Esse marco temporal foi escolhido, tomando como base o período de publicação do Boletim Catequético, periódico católico destinado à formação de professoras catequistas no Brasil, parte da tese de doutorado "Educar-se para educar: o projeto pedagógico do Monsenhor Álvaro Negromonte dirigido a professoras e famílias através de impressos (1936-1964)". Esse marco serviu como elemento norteador para pensar essas questões pedagógicas associadas à Escola Nova em 


\section{Vestígios de formação docente nas páginas da imprensa periódica educacional}

Os anos de 1930 marcam significativamente a Igreja Católica. Esse marco pode ser entendido como um divisor de águas, sobretudo pelo movimento da Ação Católica, que ampliou o escopo de ações da Igreja, permitindo novos contornos para os modos como passa a se configurar em diferentes países. Fundada em 1933 em Portugal e, em 1935, no Brasil, a Ação Católica foi um movimento que tinha como meta inserir os leigos no apostolado e reimprimir seu lugar nas duas nações, que durante o período de Primeira República, foi afastada, oficialmente de alguns espaços sociais estratégicos como o campo educacional. Além disso, em ambos os países esse período foi marcado por um contexto de ditadura, que, apesar de suas especificidades, apresentam algumas estratégias aproximadas nas relações que se estreitam entre Igreja e Estado. Nos dois países, a educação, mais do que nunca, foi vista como uma fôrma para modelar o tipo de homem que se pretendia para a sociedade.

Em Portugal, a partir de 1926, com a ditadura militar e o Estado Novo, os pedagogos portugueses que veiculavam as ideias propagadas pelas Escolas Novas, acentuando seu caráter progressista e laico, foram afastados dos cenários políticos e educacionais e silenciados, dando lugar ao grupo católico, que sob a liderança de Cruz Filipe declarou querer representar a Liga da Educação Nova em Portugal. Este grupo passou a estabelecer contato direto com as personalidades de referência internacional, afastando-as, com isso, dos renovadores progressistas portugueses. Esse movimento, no entanto, não foi unilateral e pode-se dizer que foi endossado pelo próprio Adolpho Ferrière que, ao visitar o país e ser recebido por Cruz Filipe,

Portugal no mesmo período em que vinha analisando o movimento de apropriação similar pelo grupo católico no Brasil. Ver Orlando (2013). 
não contestou os valores e a política educativa do regime salazarista, estabeleceu mesmo a conciliação entre o seu movimento e esses valores, ao mesmo tempo que criticava os desvios anarquistas [...] e afirmava que a liberdade não se opunha à autoridade (MOGARRO, 2006, p. 234).

Essa mudança visível que se estabeleceu no discurso educativo, diluiu as referências escolanovistas em prescrições técnico-didáticas utilizadas para afirmar o tripé - Deus, Pátria e família - na nação portuguesa, a partir de meados da década de 1930.

Afirmava-se uma pedagogia conservadora, nacionalista e católica: a escola era a 'sagrada oficina das almas', a autoridade do professor e a ordem social não se punham em causa, os valores e a moral católica impregnavam todos os contextos escolares e a componente técnica do ensino era fortemente afirmada, num sentido disciplinar (MOGARRO, 2006, p. 235) ${ }^{3}$

Esse marco temporal foi durante muito tempo representado na historiografia portuguesa, assim como na brasileira, pelo esvaziamento do ideário escolanovista. Todavia, pesquisas realizadas a partir dos anos de 1980 nos dois países vêm buscando compreender as permanências e os desdobramentos dos princípios escolanovistas a partir da segunda metade dos anos de 1930 e 1940 quando o grupo católico conquistava maior influência junto ao governo, nos dois países aqui abordados ${ }^{4}$.

Esses diferentes contextos alimentaram práticas e processos de produção, circulação e apropriação de modelos pedagógicos e culturais que resultaram na reconfiguração do discurso pedagógico católico, revelando alguns modos pelos quais os enunciados escolanovistas persistiram

3 Sobre esse assunto, ver também Nóvoa (1987), Mogarro (2001) e Mogarro, Pintassilgo \& Henriques (2010, 2012).

4 (Nóvoa, 1987, 1995; Mogarro, 2001; Mogarro, Pintassilgo e Henriques (2010, 2012); Carvalho, 1998; Magaldi, 2007; Sgarbi, 1997; Streak Strang, 2008; Orlando, 2013). 
nas orientações e prescrições endereçadas aos professores, sobretudo através da imprensa periódica educacional.

No Brasil, a foco da pesquisa recaiu sobre o Boletim Catequético, periódico editado pela Igreja como estratégia de difusão do pensamento católico na escola e na sociedade brasileira, mas, sobretudo, a mineira, onde foi produzido. Em Portugal, o foco da lente centrou-se em um periódico oficial do estado português, buscando compreender como o pensamento católico foi veiculado para os professores através do Estado.

O Boletim Oficial do Ensino Primário Escola Portuguesa, publicado em Portugal, pelo Ministério da Educação Nacional tinha como foco o aparelhamento dos professores, tanto do ponto de vista doutrinário quanto pedagógico e se articulavam em torno da consolidação de um campo de produção cultural que instituía, nas práticas profissionais dos professores primários, uma cultura pedagógica estabelecida em sólidas bases católicas.

Além da perspectiva doutrinária, no âmbito pedagógico uma das questões que nortearam essa pesquisa passa pela compreensão dos múltiplos modos pelos quais os princípios das Escolas Novas se fizeram presentes nas prescrições pedagógicas que foram veiculadas por expoentes do catolicismo - pertencentes tanto à hierarquia eclesiástica quanto ao laicato católico - e como estes católicos construíram uma representação específica da (e para a) profissão docente.

Com isso, os dois caminhos de investigação escolhidos nesta pesquisa indicam também dois movimentos estratégicos utilizados pela Igreja, concomitantemente, para formar o professorado nas "novas" diretrizes pedagógicas: um deles se deu pela inserção de enunciados escolanovistas nas publicações religiosas endereçadas aos professores, a fim de equiparar, pedagogicamente, o ensino religioso às outras áreas de conhecimento e colocar a doutrina cristã no rol dos saberes elementares para a educação da criança, passando primeiro pela formação dos professores; o outro movimento inseria a doutrina católica nas revistas publicadas por órgãos oficiais da Instrução Pública para os professores, aproveitando o contato que eles tiveram com o ideário escolanovista em sua formação inicial, reordenando-o 
naquilo que ferisse os princípios católicos e nacionalistas, como por exemplo, a questão da liberdade e autonomia do aluno.

Nos anos de 1920, no Brasil, as correntes escolanovistas ganharam relevo dentre os especialistas da educação que passaram a propugnar seus enunciados como "novidade" no campo educacional e instrumentos indispensáveis à renovação educacional do país. Com projetos distintos, os "Pioneiros da Educação Nova", que tinham Fernando de Azevedo e Anísio Teixeira como seus principais expoentes, defendiam uma proposta de educação laica, gratuita, obrigatória e mista, o que levou ao rompimento com os católicos que não assinaram o Manifesto dos Pioneiros da Educação Nova (1932) em prol dessa causa.

Ao romperem com seus precursores e com muitos dos seus aliados, os "pioneiros" demarcavam um espaço na memória e na História como os renovadores da educação no Brasil (CARVALHO, 1998). Paralelamente, ao romperem com os "pioneiros" e manterem um órgão de difusão do escolanovismo pela ótica católica ${ }^{5}$, os educadores deste grupo também produziram publicamente, uma marca política de renovação sem perder de vista elementos da tradição como a coeducação, e a manutenção da rede privada de ensino confessional católico. Através da leitura das correntes escolanovistas, eles reorganizaram o ensino religioso, a partir de um projeto maciço de formação de professores sob essa nova concepção, através de cursos de aperfeiçoamento para os professores, revistas doutrinárias/pedagógicas e manuais de catecismo inspirados nas contribuições oriundas das Escolas Novas, com forte acento na Psicologia da Educação, como elemento indispensável para a renovação da Pedagogia Católica.

Em outro contexto de produção, a presença da Igreja no Boletim Escola Portuguesa, permite apreender muito dessa "autonomia relativa" das instituições religiosas em relação ao Estado. A presença mais efetiva dos interesses do Estado nesse periódico, produzido pelo próprio Estado, mas ao mesmo tempo com uma orientação marcadamente católica, revela como

5 Sobre escolanovismo católico na CCBB e na Revista Brasileira de Pedagogia, ver Sgarbi (1997). 
as instituições se configuram em uma rede de interdependência que as mobiliza em prol de interesses convergentes (ELIAS, 1994).

O Boletim A Escola Portuguesa, foi um periódico semanal publicado pelo Ministério Nacional de Educação, a partir de $1934^{6}$, com o objetivo inicial de informar os professores sobre ofícios e legislações inerentes à profissão docente. Todavia, esse objetivo inicial não durou muito tempo e, rapidamente, assumiu uma feição mais pedagógica, passando a funcionar não só como veículo de informação, mas também de formação dos professores dentro da ótica estadonovista, difundindo, junto a esses profissionais, "saberes" e "modos de fazer" docentes, impregnados de valores nacionalistas e cristãos.

Nos discursos educativos que marcavam a política oficial portuguesa afirmou-se a escola como "a sagrada oficina das almas" (Salazar), onde não se discutia a autoridade do professor e a ordem social. Os valores e a moral católica impregnavam todos os contextos escolares e os dispositivos técnico-didáticos eram afirmados, com um forte sentido disciplinar (NÓVOA, 1987; MOGARRO, 2001).

Inúmeros artigos publicados por professores e técnicos da educação apresentavam prescrições para o trabalho em sala de aula, ancorados a um referencial técnico-didático escolanovista, onde o nacionalismo e o catolicismo apareciam imbricados como eixos norteadores indissociáveis da educação. Isso fazia com que os temas publicados no Boletim A Escola Portuguesa se atravessassem mutuamente, produzindo uma marca que permite compreender o grau de catolicidade no campo da educação pública em Portugal, grau esse que era mais expressivo do que no Brasil, onde pelo discurso que vigorava no Boletim Catequético se tornava evidente ser ainda necessário incutir nos professores a doutrina católica.

Em todo o Boletim A Escola Portuguesa é possível perceber os valores católicos nos discursos formativos propagados aos professores. A doutrina

6 Nessa pesquisa foram consultados os exemplares publicados entre 1934 e 1945 para tentar apreender as estratégias de difusão do pensamento católico junto ao professorado na mesma época em que se analisou o Boletim Catequético. 
cristã aparecia como uma temática própria, que servia para reforçar a mentalidade cristã do professorado à luz dos princípios escolanovistas, mas aparecia também como pano de fundo nos artigos de cunho estritamente pedagógico, nos informes que veiculavam as iniciativas sociais do Estado português e naqueles artigos que versavam sobre o perfil do professor e da escola portuguesa. Ficava evidente, também, na seção intitulada $O$ crucifixo nas escolas, onde anunciava a colocação do crucifixo em diferentes escolas primárias do território Português, reforçando a articulação entre Estado e Igreja, e sinalizando para o engajamento dos educadores na obra de reconstrução nacional, na qual deveriam servir tanto a Deus quanto à Pátria. Outra evidência pode ser vista com destaque no Editorial do número 259, que apresentava a Carta Pastoral de Sua Eminência o Patriarca de Lisboa, com quatro páginas (EP, outubro de 1939, p. 13-16). Dessa maneira, a Igreja ia se fazendo presente na educação pública portuguesa, tendo os próprios professores como seus principais porta-vozes.

Do ponto de vista pedagógico, os aportes teóricos do movimento escolanovista, foram incorporados na medida em que contribuíam diretamente para a eficácia do desenvolvimento do processo educacional. E os intelectuais católicos tornaram-se, a partir dos anos trinta, os principais elementos de mediação desse diálogo. Quatro princípios ideológicos, assim como os princípios técnico-didáticos, estavam presentes nos discursos dos pedagogos católicos sem maiores restrições e faziam convergir Pedagogia Moderna e Escolas Novas no projeto de orientação do professorado: "espontaneidade, atividade, interesse e cooperação" (LENA, 1932, p. 82). Esses princípios também podem ser aferidos das propostas pedagógicas do padre Álvaro Negromonte veiculadas no Boletim Catequético. Em ambos os casos, pode-se fazer ainda alguns acréscimos. Nos textos selecionados, foram constatados princípios de aplicação, motivação, associação, esforço pessoal, graduação, progressão sem, contudo, enfatizar o método intuitivo.

$\mathrm{O}$ aspecto fundamental dos textos selecionados no Boletim $A$ Escola Portuguesa foi o lugar nuclear conferido à educação doutrinária e moral que os professores deveriam dar aos seus alunos, chegando a constituir duas seções intituladas "Sobre o ensino da Doutrina e Sobre o ensino 
da Moral”. Em geral, as seções do Boletim A Escola Portuguesa se apresentavam como no Boletim Catequético, algumas eram fixas, outras tinham um caráter volante e apareciam esporadicamente no periódico. A questão moral teve um forte acento também nos artigos que não eram publicados em seções específicas e recebeu a atenção de diferentes professores que se propuseram a tratar desse tema ao longo de todo o período aqui elencado. No quadro abaixo foi listado um conjunto de artigos em que os temas da doutrina, moral e educação nova apareceram, atravessando-se mutuamente, formando um repertório doutrinário-pedagógico autorizado para os professores.

\section{Quadro 1 - Quadro de temas doutrinário-pedagógicos no Boletim}

Escola Portuguesa

(continua)

\begin{tabular}{|c|c|c|}
\hline Artigo & Autor & Referência \\
\hline $\begin{array}{l}\text { Para uma escola ativa de espírito } \\
\text { cristão }\end{array}$ & Seção Fatos e Comentários & $\begin{array}{l}\text { Ano I, } n=14,10 \text { de janeiro } \\
\text { de } 1935, \text { p. } 595 \text {. }\end{array}$ \\
\hline Fundamento moral da educação & Editorial & $\begin{array}{l}\text { Ano I, } n=48,05 \text { de setembro } \\
\text { de } 1935, \text { p. } 859\end{array}$ \\
\hline A preparação espiritual do mestre & Maria Montessori & $\begin{array}{l}\text { Ano II, } n=66,16 \text { de janeiro } \\
\text { de } 1936, \text { p. } 98-100 \text {. }\end{array}$ \\
\hline $\begin{array}{l}\text { A moral cristã como fator de } \\
\text { regeneração social }\end{array}$ & $\begin{array}{l}\text { Fernando Pais de } \\
\text { Figueiredo }\end{array}$ & $\begin{array}{l}\text { Ano II, } \mathrm{n}-82,7 \text { de maio de } \\
\text { 1936, p. 200-203. }\end{array}$ \\
\hline $\begin{array}{l}\text { A formação da mocidade e a defesa } \\
\text { da Pátria }\end{array}$ & Editorial & $\begin{array}{l}\text { Ano II, no } 87,11 \text { de junho de } \\
1936, \text { p. 241-244. }\end{array}$ \\
\hline $\begin{array}{l}\text { O sentido da presença do crucifixo } \\
\text { nas escolas }\end{array}$ & Dr. Carneiro Pacheco & $\begin{array}{l}\text { Ano II, no } 89,25 \text { de junho de } \\
1936 \text {, p. } 255-256 \text {. }\end{array}$ \\
\hline Do catolicismo na escola & Cunha Leão & $\begin{array}{l}\text { Ano II, no 92, } 16 \text { de julho de } \\
1936, \text { p. } 279 .\end{array}$ \\
\hline O espírito na escola & José Pereira Pinto & $\begin{array}{l}\text { Ano II, no 94, } 30 \text { de julho de } \\
\text { 1936, p. 300-302. }\end{array}$ \\
\hline $\begin{array}{l}\text { Toda a filosofia da educação deve } \\
\text { ser dominada por uma filosofia do } \\
\text { espírito }\end{array}$ & Garcia Domingues & $\begin{array}{l}\text { Ano II, no } 101,17 \text { de } \\
\text { dezembro de } 1936, \text { p. } 343 \text {, } \\
344 .\end{array}$ \\
\hline Pedagogia cristã: nótulas históricas & José Maria Gaspar & $\begin{array}{l}\text { Ano III, no } 123,04 / 03 / 1937 \text {, } \\
\text { p. } 138 .\end{array}$ \\
\hline Pedagogia cristã: nótulas históricas & José Maria Gaspar & $\begin{array}{l}\text { Ano III, no } 124,11 / 03 / 1937 \text {, } \\
\text { p. } 145 .\end{array}$ \\
\hline
\end{tabular}




\begin{tabular}{|c|c|c|}
\hline Pedagogia cristã: nótulas históricas & José Maria Gaspar & $\begin{array}{l}\text { Ano III, no } 127,01 / 04 / 1937 \text {, } \\
\text { p. } 160 \text {. }\end{array}$ \\
\hline Velha e nova escola & Domingos Evangelista & $\begin{array}{l}\text { Ano III, no 129, 15/04/1937, } \\
\text { p. } 172 \text {. }\end{array}$ \\
\hline $\begin{array}{l}\text { Ao contato de realidades: lição de } \\
\text { moral e doutrina cristã durante a } \\
\text { lição de língua materna }\end{array}$ & Felismina Oliveira & $\begin{array}{l}\text { Ano III, no 129, 15/04/1937, } \\
\text { p. } 173 .\end{array}$ \\
\hline $\begin{array}{l}\text { Pedagogia Cristã: nótulas históricas } \\
\text { (parte IV) }\end{array}$ & José Maria Gaspar & $\begin{array}{l}\text { Ano III, n-135, 27/05/1937, } \\
\text { p. } 218,219 .\end{array}$ \\
\hline $\begin{array}{l}\text { Pedagogia Cristã: nótulas históricas } \\
\text { (parte V) }\end{array}$ & José Maria Gaspar & $\begin{array}{l}\text { Ano III, no } 136,03 / 06 / 1937 \text {, } \\
\text { p. } 227,228 \text {. }\end{array}$ \\
\hline A moral na escola & Manoel Subtil & $\begin{array}{l}\text { Ano III, no 143, 22/07/1937, } \\
\text { p. } 281,282 \text {. }\end{array}$ \\
\hline $\begin{array}{l}\text { Pedagogia Cristã: nótulas históricas } \\
\text { (parte VI) }\end{array}$ & José Maria Gaspar & $\begin{array}{l}\text { Ano III, no 144, 29/07/1937, } \\
\text { p. } 288 \text {. }\end{array}$ \\
\hline A ação civilizadora do Cristianismo & Janeiro Acabado & $\begin{array}{l}\text { Ano III, no } 150,09 / 09 / 1937 \text {, } \\
\text { p. } 322-325 \text {. }\end{array}$ \\
\hline Christus Vincit & José Francisco Figueiredo & $\begin{array}{l}\text { Ano III, no 152, 23/09/1937, } \\
\text { p. 336-339. }\end{array}$ \\
\hline Christus Vincit (parte II) & José Francisco Figueiredo & $\begin{array}{l}\text { Ano III, no } 153,30 / 09 / 1937 \text {, } \\
\text { p. } 345-348 \text {. }\end{array}$ \\
\hline $\begin{array}{l}\text { Sobre o ensino da doutrina: o santo } \\
\text { patrono }\end{array}$ & $\begin{array}{l}\text { Prof. M. Nogueira } \\
\text { Gonçalves }\end{array}$ & $\begin{array}{l}\text { Ano IV, no 159, 11/111/1937, } \\
\text { p. 50-52. }\end{array}$ \\
\hline $\begin{array}{l}\text { Sobre o ensino da moral: o amor à } \\
\text { Pátria e o } 10 \text { de dezembro }\end{array}$ & $\begin{array}{l}\text { Prof. M. Nogueira } \\
\text { Gonçalves }\end{array}$ & $\begin{array}{l}\text { Ano IV, no 161, 25/11/1937, } \\
\text { p. } 80-82 \text {. }\end{array}$ \\
\hline Estado Novo- Escola Nova & Afonso da Cunha & $\begin{array}{l}\text { Ano IV, no } 163,09 / 12 / 1937 \text {, } \\
\text { p. } 120-121 .\end{array}$ \\
\hline $\begin{array}{l}\text { Sobre o esnino da moral: virtudes a } \\
\text { adquirir - a obediência }\end{array}$ & $\begin{array}{l}\text { Prof. M. Nogueira } \\
\text { Gonçalves }\end{array}$ & $\begin{array}{l}\text { Ano IV, no 164, 16/12/1937, } \\
\text { 141-142. }\end{array}$ \\
\hline $\begin{array}{l}\text { A espiritualidade da quadra de } \\
\text { Natal }\end{array}$ & Editorial & $\begin{array}{l}\text { Ano IV, no } 167,06 /-1 / 1937 \text {, } \\
\text { p. } 181-183 \text {. }\end{array}$ \\
\hline $\begin{array}{l}\text { Sobre o ensino da moral: } \mathrm{O} \text { amor } \\
\text { de Jesus pelas crianças }\end{array}$ & $\begin{array}{l}\text { Prof. M. Nogueira } \\
\text { Gonçalves }\end{array}$ & $\begin{array}{l}\text { Ano IV, no 168, 13/01/1938, } \\
\text { p. 194-196. }\end{array}$ \\
\hline $\begin{array}{l}\text { Sobre o ensino da moral: virtudes } \\
\text { a adquirir - a caridade - obras de } \\
\text { misericórdias }\end{array}$ & $\begin{array}{l}\text { Prof. M. Nogueira } \\
\text { Gonçalves }\end{array}$ & $\begin{array}{l}\text { Ano IV, no 171, 03/02/1938, } \\
\text { p. 234-236. }\end{array}$ \\
\hline As confissões de Santo Agostinho & Janeiro Acabado & $\begin{array}{l}\text { Ano IV, no 179, 31/03/1938, } \\
\text { p. } 339-340 \text {. }\end{array}$ \\
\hline A ordem cristã na pedagogia nova & José Maria Gaspar & $\begin{array}{l}\text { Ano V, no } 207,13 / 10 / 1938 \text {, } \\
\text { p. } 15,16 \text {. }\end{array}$ \\
\hline $\begin{array}{l}\text { Lições elementares de Psicologia } \\
\text { aplicada à educação }\end{array}$ & Janeiro Acabado & $\begin{array}{l}\text { Ano V, no } 218,29 / 12 / 1938 \text {, } \\
\text { p. } 142,143\end{array}$ \\
\hline
\end{tabular}


(continua)

\begin{tabular}{|c|c|c|}
\hline A formação moral dos lusitanos & Editorial & $\begin{array}{l}\text { Ano V, no 223, 02/02/1939, } \\
\text { p. } 179-180 \text {. }\end{array}$ \\
\hline Pio XI e a educação & Prof. Janeiro Acabado & $\begin{array}{l}\text { Ano V, no } 229,16 / 03 / 1939 \text {, } \\
\text { p. } 252-253 \text {. }\end{array}$ \\
\hline Crucifixo & Domingos Evangelista & $\begin{array}{l}\text { Ano V, no } 231,30 / 03 / 1939 \text {, } \\
\text { p. } 288-290 .\end{array}$ \\
\hline A atualidade de Cristo & s/assinatura & $\begin{array}{l}\text { Ano V, no 233, 13/ 04/1939, } \\
\text { p. } 314-315 \text {. }\end{array}$ \\
\hline A escola e a recristianização do país & Editorial & $\begin{array}{l}\text { Ano V, no 236, 04/05/1939, } \\
\text { p. } 361-362 \text {. }\end{array}$ \\
\hline Língua Materna: Santo Antônio & Domingos Evangelista & $\begin{array}{l}\text { Ano V, no 244, 29/06/1939, } \\
\text { p. } 494-496 .\end{array}$ \\
\hline $\begin{array}{l}\text { Valor do tradicional ensino da } \\
\text { moral }\end{array}$ & $\begin{array}{l}\text { Diário do governo (editorial } \\
\text { sem assinatura) }\end{array}$ & $\begin{array}{l}\text { Ano VI, no 258, 05/10/1939, } \\
\text { p. } 1-2 \text {. }\end{array}$ \\
\hline $\begin{array}{l}\text { Carta Pastoral de Sua Eminência o } \\
\text { Cardial Patriarca de Lisboa }\end{array}$ & $\begin{array}{l}\text { Diário do governo (editorial } \\
\text { sem assinatura) }\end{array}$ & $\begin{array}{l}\text { Ano VI, no 259, 12/10/1939, } \\
\text { p. } 13-16 \text {. }\end{array}$ \\
\hline $\begin{array}{l}\text { Psicologia Aplicada à educação - o } \\
\text { hábito }\end{array}$ & Prof. Janeiro Acabado & $\begin{array}{l}\text { Ano VI, no 262, 02/11/1939, } \\
\text { p. } 66-68 \text {. }\end{array}$ \\
\hline Ainda sobre o ensino da moral & Diário do governo & $\begin{array}{l}\text { Ano VI, no 262, 02/11/1939, } \\
\text { p. } 61,62 \text {. }\end{array}$ \\
\hline Tendências atuais da Escola Nova & Editorial & $\begin{array}{l}\text { Ano VI, no } 276,08 / 02 / 1940 \text {, } \\
\text { p. } 273-274\end{array}$ \\
\hline $\begin{array}{l}\text { Doutrina Cristã da existência de } \\
\text { Deus }\end{array}$ & Silvestre de Figueiredo & $\begin{array}{l}\text { Ano VI, no } 277,15 / 02 / 1940 \text {, } \\
\text { p. } 294,295 \text {. }\end{array}$ \\
\hline Cristo - realidade constante & Editorial & $\begin{array}{l}\text { Ano VI, no 282, 21/03/1940, } \\
\text { p.369. }\end{array}$ \\
\hline $\begin{array}{l}\text { A doutrina Cristã nas escolas: } \\
\text { Argentina- Bélgica-Estados Unidos }\end{array}$ & Artur Bivar & $\begin{array}{l}\text { Ano VI, no 289, 09/05/1940, } \\
\text { p.479-481 }\end{array}$ \\
\hline $\begin{array}{l}\text { A moral na escola primária: como } \\
\text { conceber uma lição }\end{array}$ & Adelina de Matos Rosa & $\begin{array}{l}\text { Ano VI, no } 308,19 / 09 / 1940 \text {, } \\
\text { p.727-728. }\end{array}$ \\
\hline $\begin{array}{l}\text { A ação do professor de ensino } \\
\text { primário na formação católica do } \\
\text { povo português }\end{array}$ & Augusto da Silva Pereira & $\begin{array}{l}\text { Ano VII, no 311, 10/10/1940, } \\
\text { p. } 22 .\end{array}$ \\
\hline $\begin{array}{l}\text { Problemas educativos: cooperação } \\
\text { da família com a escola }\end{array}$ & J. Nunes de Brito & $\begin{array}{l}\text { Ano VII, no 325, 16/01/1941, } \\
\text { p. } 262 \text {. }\end{array}$ \\
\hline Moral e cultura do exemplo & Gustavo de Almeida & $\begin{array}{l}\text { Ano VII, no 327, 30/01/1941, } \\
\text { p. 300-301 }\end{array}$ \\
\hline $\begin{array}{l}\text { Educação Física: base da educação } \\
\text { integral }\end{array}$ & J. Nunes de Brito & $\begin{array}{l}\text { Ano VII, no } 328,06 / 02 / 1941 \text {, } \\
\text { p. } 324-325 \text {. }\end{array}$ \\
\hline $\begin{array}{l}\text { É preciso educar sempre e pelos } \\
\text { melhores processos }\end{array}$ & $\begin{array}{l}\text { Diário do governo (editorial } \\
\text { s/assinatura) }\end{array}$ & $\begin{array}{l}\text { Ano VII, } \mathrm{n} \text { - 332, 06/03/1941, } \\
\text { p. } 393,394 \text {. }\end{array}$ \\
\hline
\end{tabular}


(continua)

\begin{tabular}{|c|c|c|}
\hline $\begin{array}{l}\text { Educação Física e recreativa: jogos } \\
\text { recreativos e o seu valor educativo }\end{array}$ & J. Nunes de Brito & $\begin{array}{l}\text { Ano VII, no 333, 13/03/1941, } \\
\text { p. } 418 .\end{array}$ \\
\hline $\begin{array}{l}\text { A escola ativa e o dinamismo do } \\
\text { mestre na escola }\end{array}$ & Maria de Jesus Mateus & $\begin{array}{l}\text { Ano VII, no } 335,27 / 03 / 1941 \text {, } \\
\text { p. } 457-458 \text {. }\end{array}$ \\
\hline $\begin{array}{l}\text { Moral e Cultura: Escola, Religião } \\
\text { e vida }\end{array}$ & Gustavo de Almeida & $\begin{array}{l}\text { Ano VII, no } 336,03 / 04 / 1941 \text {, } \\
\text { p. } 476-477 \text {. }\end{array}$ \\
\hline $\begin{array}{l}\text { Dificuldades Doutrinais: a alma } \\
\text { humana }\end{array}$ & Mestre Lisboa & $\begin{array}{l}\text { Ano VII, no } 336,03 / 04 / 1941 \text {, } \\
\text { p. } 477-479 \text {. }\end{array}$ \\
\hline $\begin{array}{l}\text { Disciplina Escolar: a conduta do } \\
\text { mestre }\end{array}$ & Sebastião Carvalho & $\begin{array}{l}\text { Ano VII, no } 338,17 / 04 / 1941 \text {, } \\
\text { p. } 518 \text {. }\end{array}$ \\
\hline Escola sem Fé & José Francisco de Moura & $\begin{array}{l}\text { Ano VII, no } 340,03 / 04 / 1941 \text {, } \\
\text { p. } 550-551 \text {. }\end{array}$ \\
\hline O catecismo nas escolas & Maria de Jesus Mateus & $\begin{array}{l}\text { Ano VII, no 342, 15/05/1941, } \\
\text { p. } 591 .\end{array}$ \\
\hline $\begin{array}{l}\text { Moral e Cultura: O mundo, nós e } \\
\text { Deus }\end{array}$ & Artur Bivar & $\begin{array}{l}\text { Ano VII, no 343, 22/05/1941, } \\
\text { p } 608 \text {. }\end{array}$ \\
\hline Conceito de professor & Fernandes de Carvalho & $\begin{array}{l}\text { Ano VII, no } 343,22 / 05 / 1941 \text {, } \\
\text { p. } 609-610\end{array}$ \\
\hline Práticas Educativas & $\begin{array}{l}\text { Aníbal Augusto da Silva } \\
\text { Pereira }\end{array}$ & $\begin{array}{l}\text { Ano VII, no 343, 22/05/1941, } \\
\text { p.611. }\end{array}$ \\
\hline $\begin{array}{l}\text { Moral e Cultura: a verdade e a } \\
\text { beleza dos Evangelhos }\end{array}$ & Clotilde Mateus & $\begin{array}{l}\text { Ano VII, no } 344,29 / 05 / 1941 \text {, } \\
\text { p. } 631,632 \text {. }\end{array}$ \\
\hline $\begin{array}{l}\text { Moral e Cultura: Notas } \\
\text { bibliográficas }\end{array}$ & Gustavo de Almeida & $\begin{array}{l}\text { Ano VII, no } 345,05 / 06 / 1941 \text {, } \\
\text { p. } 643,644 \text {. }\end{array}$ \\
\hline Educar... & Maria de Jesus Mateus & $\begin{array}{l}\text { Ano VII, no } 347,19 / 06 / 1941 \text {, } \\
\text { p. } 681,682 \text {. }\end{array}$ \\
\hline O pároco e o professor & José Maria Gaspar & $\begin{array}{l}\text { Ano VII, no } 347,19 / 06 / 1941 \text {, } \\
\text { p. } 682,683 \text {. }\end{array}$ \\
\hline Catecismo & Maria da Assunção Ochôa & $\begin{array}{l}\text { Ano VII, no } 348,26 / 06 / 1941 \text {, } \\
\text { p. } 695 \text {. }\end{array}$ \\
\hline $\begin{array}{l}\text { A verdade e a beleza dos } \\
\text { Evangelhos }\end{array}$ & Clotilde Mateus & $\begin{array}{l}\text { Ano VII, } \mathrm{n}=350,10 / 07 / 1941 \text {, } \\
\text { p. } 726 \text {. }\end{array}$ \\
\hline $\mathrm{Na}$ esteira da moral & Barata dos Santos & $\begin{array}{l}\text { Ano VII, no 354, 07/08/1941, } \\
\text { p. } 788 \text {. }\end{array}$ \\
\hline A formação cristã das crianças & M.O. & $\begin{array}{l}\text { Ano VII, no } 362,02 / 10 / 1941 \text {, } \\
\text { p. } 868 \text {. }\end{array}$ \\
\hline $\begin{array}{l}\text { O ensino do catecismo na escola } \\
\text { primária }\end{array}$ & Clotilde Mateus & $\begin{array}{l}\text { Ano VIII, no } 365 \text {, } \\
23 / 10 / 1941, \text { p. } 40,41\end{array}$ \\
\hline A escola e a felicidade da criança & Editorial & $\begin{array}{l}\text { Ano VII, no } 368,13 / 11 / 1941 \text {, } \\
\text { p. } 93-95 \text {. }\end{array}$ \\
\hline $\begin{array}{l}\text { Educação física infantil: jogos } \\
\text { infantis e seu valor educativo }\end{array}$ & J. Nunes de Brito & $\begin{array}{l}\text { Ano VIII, no 364, } \\
\text { 16/10/1941, p.27,28. }\end{array}$ \\
\hline
\end{tabular}


(continua)

\begin{tabular}{|c|c|c|}
\hline $\begin{array}{l}\text { Educação Física: sua necessidade e } \\
\text { importância }\end{array}$ & J. Nunes de Brito & $\begin{array}{l}\text { Ano VIII, no } 368 \\
13 / 11 / 1941 \text {, p. } 99,100 \text {. }\end{array}$ \\
\hline $\begin{array}{l}\text { A família de Nazaré modelo } \\
\text { permanente das famílias }\end{array}$ & $\begin{array}{l}\text { Diário do governo } \\
\text { (editorial s/assinatura) }\end{array}$ & $\begin{array}{l}\text { Ano VIII, no } 375 \\
\text { 01/01/1942, p. } 213,214 \text {. }\end{array}$ \\
\hline Doutrina cristã (plano de lição) - I & Clotilde Mateus & $\begin{array}{l}\text { Ano VIII, no } 376 \text {, } \\
08 / 01 / 1942, \text { p. } 236,237 \text {. }\end{array}$ \\
\hline O catecismo em lições práticas - II & Clotilde Mateus & $\begin{array}{l}\text { Ano VIII, no } 377 \\
15 / 01 / 1942, \text { p. } 249,250 \text {. }\end{array}$ \\
\hline O catecismo em lições práticas - III & Clotilde Mateus & $\begin{array}{l}\text { Ano VIII, no } 378 \text {, } \\
\text { 22/01/1942, p. } 265,266 \text {. }\end{array}$ \\
\hline Doutrina cristã - IV & Clotilde Mateus & $\begin{array}{l}\text { Ano VIII, no } 381 \\
12 / 02 / 1942, \text { p. } 315,316 \text {. }\end{array}$ \\
\hline Doutrina cristã - V & Clotilde Mateus & $\begin{array}{l}\text { Ano VIII, no } 383 \text {, } \\
26 / 02 / 1942, \text { p. } 348,349 \text {. }\end{array}$ \\
\hline Escola Nova & Mario Sanches & $\begin{array}{l}\text { Ano VIII, no } 395 \text {, } \\
21 / 05 / 1942 \text {, p. } 536,537 \text {. }\end{array}$ \\
\hline A cultura ética na escola primária - & Silvestre de Figueiredo & $\begin{array}{l}\text { Ano IX, no } 423,03 / 12 / 1942, \\
\text { p. } 187,188 .\end{array}$ \\
\hline $\begin{array}{l}\text { A cultura ética na escola primária } \\
\text { (parte II) - }\end{array}$ & Silvestre de Figueiredo & $\begin{array}{l}\text { Ano IX, no } 425,17 / 12 / 1942 \text {, } \\
\text { p. } 218,219 .\end{array}$ \\
\hline $\begin{array}{l}\text { A cultura ética na escola primária } \\
\text { (parte III) }\end{array}$ & Silvestre de Figueiredo & $\begin{array}{l}\text { Ano IX, no 426, 24/12/1942, } \\
\text { p. } 233 .\end{array}$ \\
\hline $\begin{array}{l}\text { A cultura ética na escola primária } \\
\text { (parte IV) }\end{array}$ & Silvestre de Figueiredo & $\begin{array}{l}\text { Ano IX, no } 427,31 / 12 / 1942 \text {, } \\
\text { p. } 248,249 \text {. }\end{array}$ \\
\hline $\begin{array}{l}\text { A cultura ética na escola primária } \\
\text { (parte V): a obediência }\end{array}$ & Silvestre de Figueiredo & $\begin{array}{l}\text { Ano IX, no 428, 07/01/1943, } \\
\text { p. } 261,262 .\end{array}$ \\
\hline $\begin{array}{l}\text { A cultura ética na escola primária } \\
\text { (parte VI) - o ensino moral }\end{array}$ & Silvestre de Figueiredo & $\begin{array}{l}\text { Ano IX, no } 433,11 / 02 / 1943 \text {, } \\
\text { p. } 345,346 .\end{array}$ \\
\hline $\begin{array}{l}\text { A cultura ética na escola primária } \\
\text { (parte VII) - o exemplo }\end{array}$ & Silvestre de Figueiredo & $\begin{array}{l}\text { Ano IX, no } 438,18 / 03 / 1943 \text {, } \\
\text { p. } 438-439 \text {. }\end{array}$ \\
\hline $\begin{array}{l}\text { A cultura ética na escola primária } \\
\text { (parte VIII) - o comportamento e } \\
\text { os prêmios }\end{array}$ & Silvestre de Figueiredo & $\begin{array}{l}\text { Ano IX, no } 439,2 / 03 / 1943 \text {, } \\
\text { p. } 456,457 .\end{array}$ \\
\hline $\begin{array}{l}\text { A cultura ética na escola primária } \\
\text { (parte IX) - a natureza também } \\
\text { educa }\end{array}$ & Silvestre de Figueiredo & $\begin{array}{l}\text { Ano IX, no 446, 13/05/1943, } \\
\text { p. } 577 .\end{array}$ \\
\hline $\begin{array}{l}\text { A Psicologia a serviço da } \\
\text { elaboração do livro pedagógico }\end{array}$ & Mário Gonçalves Viana & $\begin{array}{l}\text { Ano IX, no } 458,05 / 08 / 1943 \text {, } \\
\text { p. } 764,765 \text {. }\end{array}$ \\
\hline $\begin{array}{l}\text { Os livros para crianças dos sete aos } \\
\text { dez anos }\end{array}$ & Mário Gonçalves Viana & $\begin{array}{l}\text { Ano IX, no } 462,02 / 09 / 1943 \text {, } \\
\text { p. } 811,812 .\end{array}$ \\
\hline $\begin{array}{l}\text { A classificação dos livros infantis e } \\
\text { os esquemas de bibliotecas }\end{array}$ & Mário Gonçalves Viana & $\begin{array}{l}\text { Ano IX, no } 463,09 / 09 / 1943 \text {, } \\
\text { p. } 819,820 .\end{array}$ \\
\hline
\end{tabular}


(continua)

\begin{tabular}{|c|c|c|}
\hline A criança e o professor & Mário Gonçalves Viana & $\begin{array}{l}\text { Ano IX, no } 465,23 / 09 / 1943 \text {, } \\
\text { p. } 839,840 .\end{array}$ \\
\hline $\begin{array}{l}\text { A cultura ética na escola primária } \\
\text { (parte } X \text { ) - os jardins escolares }\end{array}$ & Silvestre de Figueiredo & $\begin{array}{l}\text { Ano X, no 468, 14/10/1943, } \\
\text { p. } 19,20 .\end{array}$ \\
\hline A mentira e a escola & Mário Gonçalves Viana & $\begin{array}{l}\text { Ano } X, n=474,25 / 11 / 1943 \text {, } \\
\text { p. } 119,120 .\end{array}$ \\
\hline O Natal, a Família e a Escola & Editorial (sem assinatura) & $\begin{array}{l}\text { Ano X, no } 477,16 / 12 / 1943 \text {, } \\
\text { p. } 169,170 \text {. }\end{array}$ \\
\hline $\begin{array}{l}\text { A mentira e a escola (Como } \\
\text { combater a mentira) }\end{array}$ & Mário Gonçalves Viana & $\begin{array}{l}\text { Ano X, no 478, 23/12/1943, } \\
\text { p. } 190,191 .\end{array}$ \\
\hline $\begin{array}{l}\text { A cultura ética na escola primária } \\
\text { (Brincando se educa) }\end{array}$ & Silvestre de Figueiredo & $\begin{array}{l}\text { Ano X, no 479, 30/12/1943, } \\
\text { p. } 208,209 .\end{array}$ \\
\hline $\begin{array}{l}\text { A cultura ética na escola primária } \\
\text { (pelo canto coral) }\end{array}$ & Silvestre de Figueiredo & $\begin{array}{l}\text { Ano X, no } 481,13 / 01 / 1944 \text {, } \\
\text { p. } 235,236 .\end{array}$ \\
\hline O professor e a criança & Mario Gonçalves Viana & $\begin{array}{l}\text { Ano X, no } 484,03 / 02 / 1944 \text {, } \\
\text { p. } 281,282 \text {. }\end{array}$ \\
\hline Os pais e os mestres & Alfredo Cabral & $\begin{array}{l}\text { Ano X, no } 484,03 / 02 / 1944 \text {, } \\
\text { p. } 282,283 \text {. }\end{array}$ \\
\hline $\begin{array}{l}\text { A cultura ética na Escola Primária - } \\
\text { Previdência e assistência }\end{array}$ & Silvestre de Fiqueiredo & $\begin{array}{l}\text { Ano X, no 491, 23/03/1944, } \\
\text { p. } 395,396 .\end{array}$ \\
\hline $\begin{array}{l}\text { A salutar influência dos lavores } \\
\text { femininos }\end{array}$ & Silvestre de Fiqueiredo & $\begin{array}{l}\text { Ano X, no 499, 18/05/1944, } \\
\text { p. } 511,512 \text {. }\end{array}$ \\
\hline A missão do professor & Mário Gonçalves Viana & $\begin{array}{l}\text { Ano X, no 504, 22/06/1944, } \\
\text { p. } 584,585\end{array}$ \\
\hline $\begin{array}{l}\text { A educação cristã na Escola } \\
\text { Primária }\end{array}$ & Antônio José Mateus & $\begin{array}{l}\text { Ano X, no 509, 27/07/1944, } \\
\text { p. } 675 \text {. }\end{array}$ \\
\hline $\begin{array}{l}\text { Diretrizes pedagógicas - a } \\
\text { importância da observação na } \\
\text { escola }\end{array}$ & Mario Gonçalves Viana & $\begin{array}{l}\text { Ano X, no 509, 27/07/1944, } \\
\text { p. } 669,670 .\end{array}$ \\
\hline $\begin{array}{l}\text { Diretrizes pedagógicas - a } \\
\text { repressão dos defeitos infantis e a } \\
\text { criação dos bons hábitos }\end{array}$ & Mario Gonçalves Viana & $\begin{array}{l}\text { Ano X, no } 511,10 / 08 / 1944 \text {, } \\
\text { p. } 697,698 \text {. }\end{array}$ \\
\hline $\begin{array}{l}\text { Diretrizes pedagógicas - como } \\
\text { deve educar-se a atenção }\end{array}$ & Mario Gonçalves Viana & $\begin{array}{l}\text { Ano X, no } 514,31 / 08 / 1944 \text {, } \\
\text { p. } 729,730 \text {. }\end{array}$ \\
\hline $\begin{array}{l}\text { Diretrizes pedagógicas - as lições } \\
\text { mais úteis }\end{array}$ & Mario Gonçalves Viana & $\begin{array}{l}\text { Ano X, no } 516,14 / 09 / 1944 \text {, } \\
\text { p. } 749,750 .\end{array}$ \\
\hline $\begin{array}{l}\text { Diretrizes pedagógicas - a } \\
\text { mecanização do ensino }\end{array}$ & Mario Gonçalves Viana & $\begin{array}{l}\text { Ano X, no 519, 05/10/1944, } \\
\text { p.19,20. }\end{array}$ \\
\hline
\end{tabular}


(conclusão)

$\begin{array}{lll}\begin{array}{l}\text { Pelas vantagens do método: a } \\ \text { educação integral }\end{array} & \text { Silvestre de Figueiredo } & \begin{array}{l}\text { Ano XI, no 539, 22/02/1945, } \\ \text { p. 334,335 }\end{array} \\ \begin{array}{l}\text { Educação Cívica } \\ \text { Conselho aos professores }\end{array} & \text { Mário Gonçalves Viana } & \begin{array}{l}\text { Ano XI, no 554, 07/06/1945, } \\ \text { p. 562, 563. }\end{array} \\ \text { Diário do governo } & \begin{array}{l}\text { Ano XII, no 582, 20/12/1945, } \\ \text { p. 189,190. }\end{array} \\ \text { O professor e o meio } & \text { J. Fernandes de Carvalho } & \begin{array}{l}\text { Ano XII, no 583, 27/12/1945, } \\ \text { p. 223, 224. }\end{array}\end{array}$

Fonte: Orlando \& Mogarro (2012).

Pode-se dizer que, ao longo de sua história e em diferentes países, a profissão docente se organizou e se constituiu como um campo não apenas pedagógico, mas também, um campo de produção e mediação cultural. Do ponto de vista pedagógico, ela apresenta "as vantagens de se adotar uma postura que tenha em conta o sentido da tradição" (PINTASSILGO, 2011, p.20). Para Hansen (2001), essa postura permite duas marcas importantes: um relativo distanciamento dos modismos pedagógicos, sendo capaz de avaliá-los melhor e a expressão de uma "sabedoria" de uma comunidade particular no seu esforço de atribuir sentido ao ato de ensinar.

Do ponto de vista cultural, é possível perceber uma dimensão moral que norteia o trabalho dos professores e encontra eco na tradição das representações constituídas em torno da profissão. Essa dimensão permite compreende como o discurso pedagógico de formação dos professores foca no tema da exemplaridade do mestre, independente do momento ou do grupo que o produz.

Este enraizamento da profissão numa tradição moral é uma referência constante nos discursos de professores e pedagogos. A pessoa do aluno, e o respeito que esta deve merecer, surge como ponto de partida essencial. O professor é o em função do seu aluno. É isso que dá sentido à dicotomia clássica, de fundo religioso, mestre - discípulo. É isso, igualmente, que sustenta a definição do professor como 
educador. O crescimento integral da criança ou do jovem representa o compromisso do professor e este investe plenamente a sua pessoa na consecução desse desiderato (PINTASSILGO, 2011, p. 20,21).

O Boletim Catequético está recheado desse tipo de discurso. A força do exemplo servia para fazer a professora viver em consonância com aquilo que ensinava, tornando-se para seus alunos boas referências a serem imitadas. A eloquência necessária para o seu desempenho em sala viria da força de uma vida verdadeiramente cristã. Tais doutrinas e exigências estimulavam também um processo de autorregulação nas professoras, que não deveriam ensinar apenas aos seus alunos a regularem e controlarem suas pulsões. Antes, deveriam controlar-se a si mesmas, as suas próprias paixões e regularem suas vidas pelo código comportamental que ensinavam. Seus maiores reguladores externos não seriam os padres, distantes da sua realidade em sala, mas seus alunos, presentes constantemente no seu cotidiano. Esse controle dos impulsos e das ações cotidianas como a fala, o trato, o comportamento ou o simples modo de se vestir configuram um mecanismo disciplinar (FOUCAULT, 1998), que age em uma dupla dimensão: disciplina interna que tem um caráter de autoregulação (ELIAS, 1990) e uma disciplina externa aplicada pela presença coercitiva dos seus alunos. Outros dispositivos são utilizados ainda com essa finalidade disciplinar como a meditação, o exame de consciência, a leitura espiritual, a confissão, a comunhão e a frequência à missa.

Essas aproximações entre os dois periódicos esboçados neste artigo indiciam um modelo de Pedagogia e um perfil de educador que extrapolava os limites da Geografia, fazendo circular através do campo da produção cultural representações católicas de educação, Pedagogia e profissão docente, em dois projetos de educação nacional, que tinha o catolicismo como seu principal pilar. Quanto à apropriação do ideário da Escola Nova, pode-se dizer que esta foi uma prática inerente à vida profissional desses professores, desde a sua formação nos Cursos Normais. 


\section{Considerações Finais}

A pesquisa empreendida permitiu verificar que os projetos educacionais veiculados pelos católicos, tanto no Brasil quanto em Portugal, se valeu de uma amálgama de várias fôrmas para instituir um projeto de educação eficaz em sintonia com os princípios dos regimes de cada país. Além disso, no Brasil, apesar de contar com o apoio do Estado, a apropriação católica das correntes escolanovistas foi difundida através de iniciativas privadas elaboradas por agentes do corpo eclesiástico ou do laicato católico. Já em Portugal, essa apropriação encontra no Estado o seu maior difusor, estabelecendo junto ao professorado o "modelo" pedagógico oficial escolhido para o trabalho docente. Tais diferenças possuem sentidos que apontam, no Brasil, para um projeto de catolicização da sociedade endossado pelo Estado, enquanto em Portugal, a colaboração entre Estado e Igreja aparece de forma ainda mais estreita e em dimensões mais profundas.

O recorte aqui empreendido buscou compreender tanto do ponto de vista doutrinário quanto pedagógico como os princípios das Escolas Novas se fizeram presentes nas prescrições veiculadas por expoentes do catolicismo pertencentes tanto à hierarquia eclesiástica quanto ao laicato católico e qual a representação que os católicos construíram para a profissão docente. $\mathrm{O}$ aspecto fundamental dos textos selecionados no Boletim A Escola Portuguesa evidencia o lugar nuclear conferido à educação doutrinária e moral que os professores deveriam dar aos seus alunos, ao mesmo tempo que também os colocavam como alvo do Estado e da Igreja na configuração desse modelo. Em ambos os países, o uso dos impressos com a finalidade de contribuir para a formação de professores deixa realçar a importância dessa cultura material e do lugar que ela foi ocupando no conjunto das estratégias e táticas que foram se instaurando no processo de circulação e apropriação de modelos culturais e pedagógicos. 


\section{Referências}

CARVALHO, M. M. C. (1998) Molde Nacional e fôrma cívica: higiene, moral e trabalho no projeto da Associação Brasileira de Educação (1924-1931). Bragança Paulista: EDUSF.

ELIAS, N. Sociedade dos Indivíduos. Rio de Janeiro: Jorge Zahar Editora, 1994.

FOUCAULT, M. A governamentalidade. Microfísica do poder. Rio de Janeiro: Graal, 1998.

HANSEN, D. T. Exploring the moral heart of teaching. Toward a teacher's creed. New York and London: Teachers College Press, 2001.

LENA, A. de. A Escola Nova. Brotéria Revista contemporânea de cultura, Lisboa, vol. XV, fasc. 2-3, p. 81-87, 1932.

MAGALDI, A. M. B. M. Lições de Casa: discursos pedagógicos destinados à família no Brasil. Belo Horizonte: Argumentvm, 2007.

MOGARRO, M. J. A formação de professores no Portugal contemporâneo - A Escola do Magistério primário de Portalegre, 2001. Tese (Doutorado em Educação), Instituto de Ciencias de Educación de la Universidad de Extremadura, 2001.

. Escolanovismo e modelo católico de leitura na circulação e apropriação de modelos culturais: os manuais brasileiros nas bibliotecas de formação de professores de Portugal. In: Anais do IV Congresso Brasileiro de História da Educação: A educação e os seus sujeitos na história, Goiânia: Universidade Católica de Goiás/SBHE, v. 1. p. 1-20, 2006.

MOGARRO, M. J.; PINTASSILGO, J. \& HENRIQUES, R. P. Das escolas normais às escolas do magistério primário: percurso institucional e enquadramento legal. In J. Pintassilgo (Coord.). As escolas de formação de professores em Portugal: história, arquivo, memória. Lisboa: Colibri, 2012, p. 7-42

NÓVOA, A. Le Temps des Professeurs - Analyse socio-historique de la profession enseignante au Portugal (XVIIIe-XXe siécle). Lisboa: Instituto Nacional de Investigação Científica, 1987. 
. Uma Educação que se diz nova? In: A. Candeias, A. Nóvoa, M. H. Figueira. Sobre a Educação Nova: cartas de Adolfo Lima a Álvaro Viana de Lemos (1923-1941). Lisboa: Educa, 1995, p. 25-41.

ORLANDO, E.; MOGARRO, M. J. Fôrmas e sentidos de educar: Escola Nova católica e formação docente em dois projetos de educação nacional. In: IX Congresso Luso-Brasileiro de História da Educação: Rituais, Espaços \& Patrimônios Escolares, Anais do IX Congresso Luso-Brasileiro de História da Educação: Rituais, Espaços \& Patrimônios Escolares. Lisboa: Editora da Universidade de Lisboa, p. 01-12, 2012.

ORLANDO, E. "Educar-se para educar: o projeto pedagógico do Monsenhor Álvaro Negromonte dirigido a professoras e famílias através de impressos (19361964). 2013. Tese (Doutorado em Educação) Universidade do Estado do Rio de Janeiro, Rio de Janeiro, 2013.

PINTASSILGO, J. História da Formação de Professores. Lisboa: Instituto de Educação da Universidade de Lisboa, 2011.

PINTASSILGO, J. (Coord.). As escolas de formação de professores em Portugal: história, arquivo, memória. Lisboa: Colibri, 2012.

PINTASSILGO, J. \& MOGARRO, M.J. \& HENRIQUES, R. P. A formação de professores em Portugal. Lisboa: Colibri, 2010.

SGARBI, A. D. Igreja, Educação e Modernidade na década de 30: escolanovismo católico construído na CCBE divulgado pela Revista Brasileira de Pedagogia. 1997. Dissertação (Mestrado), Pontifícia Universidade Católica de São Paulo: São Paulo, 1997.

STRANG, B. L. S. (2008). O saber e o credo: os intelectuais católicos e a doutrina da Escola Nova (1924-1940). 2008. Tese (Doutoramento), Pontifícia Universidade Católica do Rio de Janeiro, Rio de Janeiro, 2008.

Recebido: 20/07/2015

Received: 07/20/2015

Aprovado: 08/10/2015

Approved : 10/08/2015 
